\title{
A Cautionary Tale: How Co-Constructed Work Obligations Lead to ICT- Related Technostress
}

\author{
Raluca Stana \\ IT University of Copenhagen \\ $\underline{\text { rala } @ \text { itu.dk }}$
}

\author{
Hanne Westh Nicolajsen \\ IT University of Copenhagen \\ hwni@itu.dk
}

\begin{abstract}
Technostress is a growing area of research and $a$ concern for practitioners. So far, IS research on technostress has focused on either neurophysiological or psychological measurements. We argue for a sociological approach that allows us to reveal the socially co-created obligations around using ICTs (information and communication technologies). We ask, "What can the sociological analytical concept of obligation reveal about ICT related technostress in organizations?" To investigate this question, we use the sociological concept of obligation. We conduct interpretative research based on qualitative interviews. We contribute to IS technostress research by employing the analytical lens of obligation, which allows us to find that employees see technostress as their individual obligation and devise strategies to avoid it. These strategies add to their technostress and augment group obligations that can lead to technostress for the collective. Furthermore, we find that tensions between overlapping obligations that cannot be carried out simultaneously augment technostress.
\end{abstract}

\section{Introduction}

Technostress represents any negative impact on attitudes, affects, thoughts, behaviors, or bodily physiology caused by technology directly or indirectly [1]. Technostress is an increasingly important research area within IS (Information Systems) [e.g., 2-4].

Research shows that ICT usage in organizations leads to technostress [e.g., 2,5,6]. Considering that a knowledge worker might spend up to $5.5 \mathrm{~h}$ a day on communication-related work instances [7] makes the need to look closer at ICT-related technostress even more pressing.

Taking email as an example of ICT, too little or too much email usage compared to employee desires increases technostress among employees [8]. At the same time, research on email claims that email has become a symbol of stress that distracts us from what creates stress, which can be the norm of responsiveness arising from the social context of email use, and not the medium itself [9]. Along the same line of thought, Mazmanian, Orlikowski, and Yates (2013) demonstrate that, among knowledge workers, email usage leads to a continuous tension between perceived autonomy and work norms. In other words, knowledge workers feel that they have autonomy over their email use, and they choose to exercise that autonomy by being available outside working hours, without being aware of how the norm of responsiveness impacts their decision and others'.

Past research on technostress follows different streams. One stream focuses on technostress as an individual's response to interaction with technology [e.g., 10]. Another stream focuses on ICTs in order to identify the technostress stimuli [e.g., 5,6]. A third stream is based on assumptions that technostress arises in the interaction between the individual and the ICTs [e.g., 4].

These streams of research leave out the social arena, where obligations (conscious or unconscious) are negotiated [11,12] and where norms and obligations related to the use of ICTs and their material properties are co-created [13]. We focus on how obligations shape employees' habits and how this affects their experience of technostress.

We argue that a sociological approach is crucial in technostress research, as it contributes to a more profound understanding of how technostress affects knowledge workers and the organizational milieu. We cast light on the relationship between technostress and employees' obligations. Organizational recognition and articulation may move employees' obligations from the realm of unconscious habits, as Ross (1970) calls them, to the group's political arena, where these habits can be discussed and changed. We argue that changing obligation-based habits related to ICT use is 
a meaningful way for organizations to work with technostress.

We ask, "What can the sociological analytical concept of obligation reveal about ICT-related technostress in organizations?"

To investigate this question, we use the concept of obligation as an unlocking device to unfold employees' experiences of technostress. We define obligation as the conscious or unconscious feeling that we owe something to others, ourselves, or the organization [11].

We conduct interpretative research based on qualitative interviews and employ a hermeneutical approach in our analysis. Our data consists of interviews with 10 employees from two private organizations in Denmark.

Our findings suggest that employees see technostress as their individual obligation, and they devise obligation-based habits to evade technostress. For instance, they engage in constantly checking their ICTs, even when on vacation or free time, as they want to avoid feeling overwhelmed upon returning to work. Employees' overwhelm is caused by the number of emails, their lack of overview of their task, or the burden they feel for colleagues who might be awaiting their answers. Additionally, our data suggest tensions in the obligations felt by employees. For example, employees might experience a clash between their individual obligation to be reachable and the need to engage in focused work, as they cannot carry out these two obligations simultaneously. These individual obligations and obligation-based habits lead to group obligations, as we demonstrate and discuss in our analysis and discussion chapters.

These findings are theoretically advancing our comprehension of technostress because they reveal how our individual obligations shape our habits and affect group obligations, and how group obligations in return affect individual obligation.

The paper is structured as follows: we first discuss technostress and obligation, which constitute this paper's theoretical background. Next, we present our methodology for conducting this study. We then present our analysis results, which we follow with a discussion of our theoretical background. Finally, we conclude and present the limitations of this study.

\section{Theoretical background}

\subsection{Technostress}

Stress is part of our daily lives. A certain level of stress is needed for motivation, growth, or development, also known as eustress [14] or techno eustress [3]. However, unmanageable (techno)stress damages both our mental and physical health [15]. In our research, we focus on unmanageable technostress.

We begin by drawing from the technostresscreating conditions described in Tarafdar et al. (2011), which are predominant in technostress research; see Table 1 .

Table 1. Technostress-creating conditions

\begin{tabular}{|l|l|}
\hline $\begin{array}{l}\text { Technostress- } \\
\text { creating } \\
\text { condition }\end{array}$ & Definition \\
\hline $\begin{array}{l}\text { Techno- } \\
\text { overload }\end{array}$ & $\begin{array}{l}\text { Employees face information } \\
\text { overload and ICT-enabled } \\
\text { multitasking, resulting in } \\
\text { information overload, } \\
\text { interruptions, and multitasking. }\end{array}$ \\
\hline $\begin{array}{l}\text { Techno- } \\
\text { invasion }\end{array}$ & $\begin{array}{l}\text { Employees never feel free of ICTs, } \\
\text { as they can potentially be reached } \\
\text { anywhere or anytime, and feel the } \\
\text { need to be connected continuously. }\end{array}$ \\
\hline $\begin{array}{l}\text { Techno- } \\
\text { complexity }\end{array}$ & $\begin{array}{l}\text { Employees feel intimidated by the } \\
\text { complexity of ICTs and feel forced } \\
\text { to spend time learning and } \\
\text { understanding how to best use } \\
\text { ICTs. }\end{array}$ \\
\hline $\begin{array}{l}\text { Techno- } \\
\text { uncertainty }\end{array}$ & $\begin{array}{l}\text { Employees feel unsettled by } \\
\text { continual learning, upgrades, and } \\
\text { ICT changes. }\end{array}$ \\
\hline $\begin{array}{l}\text { Techno- } \\
\text { insecurity }\end{array}$ & $\begin{array}{l}\text { Employees feel insecure about } \\
\text { their jobs in the face of new ICTs } \\
\text { and others who might know more } \\
\text { about these technologies. }\end{array}$ \\
\hline
\end{tabular}

The approach in Tarafdar et al. (2011) can be considered a psychological approach to technostress. The psychological approach stems from quantitative measurements of the individuals' conscious appraisal of what they find stressful in their interactions with technology [e.g., 3,5,6].

A more recent research approach, which can be used either complementarily or alternatively to the psychological approach, is the neurophysiological approach [16], which focuses on neurophysiological measurements such as heart rate variability (HRV) [e.g., 17] or changes in salivary stress hormone [e.g., $10]$.

In our paper, we propose a sociological approach. We argue that some covert or overt obligations are technostress creators. IS technostress research has focused on technostress creators, which so far have been identified as either technological (e.g., usability [5]) or individual (e.g., personality [18]). We hypothesize obligation as a sociological technostress creator, which, to our best knowledge, has not been pointed out in previous research. We highlight that 
individual and group obligations can lead to obligation-based habits. These may contribute to technostress. For example, an individual obligation to not delay others or a norm of responsiveness (group obligation) can lead to an obligation-based habit of constantly checking emails from home (constant connectivity). Constant connectivity is related to techno-invasion, a recognized technostress creator [6].

We highlight that a sociological approach exists in, for example, Organization Science research by Mazmanian et al. (2013) or Barley et al. (2011), with an emphasis on email and norms. They argue that it is not the IT artifact that causes technostress, but the socio-material entanglement between the individual, the technology, and the social norms surrounding this interaction. Additionally, they point out that employees might treat the resulting norms as objective constraints, thus indicating that the individual or the organization doesn't feel they have agency over these constraints.

We argue that these studies focus on the technooverload-creating dimension of technostress specific to email. Our research differs in that we expand our focus to all five technostress-creating dimensions recognized by Tarafdar et al. (2011), and to all ICTs. Furthermore, we use the sociological concept of obligations as opposed to norms.

Norms are rules that employees adhere to; for example, if others are answering emails during weekends, employees feel they should also do so. The concept of obligation differs in that it allows us to look more profoundly at the root cause of such decisions: employees might answer emails because they feel they owe something to themselves (they feel it is their individual obligation), their peers, or the organization (group obligation). The repeated action of answering emails from home as a result of an individual or group obligation might lead to an obligation-based habit.

\subsection{Obligation}

Inspired by Clark (1990), we define obligation as the conscious or unconscious feeling that we owe (or ought to do) something for others, ourselves, or the organization we work for. In addition, an obligation is a law of reciprocity or a give-and-take in everyday interactions. We summarize the concepts used in this study in Table 2, "Obligation categories."

Table 2. Obligation categories

\begin{tabular}{|l|l|}
\hline Concepts & Description \\
\hline $\begin{array}{l}\text { Individual } \\
\text { obligations }\end{array}$ & $\begin{array}{l}\text { A sense of duty and/or responsibility } \\
\text { that we build in ourselves, } \\
\text { consciously or unconsciously, of }\end{array}$ \\
\hline
\end{tabular}

\begin{tabular}{|l|l|}
\hline & $\begin{array}{l}\text { owing something to ourselves or our } \\
\text { social group(s) [12,19] (e.g., the duty } \\
\text { to not delay our colleagues). }\end{array}$ \\
\hline $\begin{array}{l}\text { Group } \\
\text { obligations }\end{array}$ & $\begin{array}{l}\text { A set of obligations (covert or overt) } \\
\text { that ensures a social group's cohesion } \\
\text { and health [19] (e.g., being reachable). }\end{array}$ \\
\hline $\begin{array}{l}\text { Obligation- } \\
\text { based } \\
\text { habits }\end{array}$ & $\begin{array}{l}\text { Unconscious or conscious } \\
\text { embodiments of our individual or } \\
\text { group obligations [12] (e.g., checking } \\
\text { emails constantly). }\end{array}$ \\
\hline
\end{tabular}

Bergson (1977) states that the nature of obligation is to integrate the individual into the social group and thereby ensure the group's health and cohesion. Looking at the individual, Bergson (1977) argues that obligation has its source in the sense of duty we build in ourselves, and that feeling obligated outward or toward others would not be enough unless we cultivated that sense of obligation in ourselves as well. Ross (1970) calls this individual obligation, which is regarding one's self as obligated to do something instead of merely inheriting group obligations.

According to Bergson (1977), our social lives consist of interlocking obligations toward society, profession, or family, and these obligations become quotidian by being embodied in our daily habits, for example, answering emails from home. Ross (1970) adds that most obligations are intuited and felt and are accepted only in the sense that we feel impelled to carry them out, but not that we are necessarily conscious of them. Bergson (1977) points out that we have an inner resistance to not carrying out our obligations. If we do decide not to perform them, this might even lead to shame, guilt, or blame [11].

Additionally, Clark (1990) presents another mechanism of integrating the individual into the group that might add to our inner resistance to not carrying out our obligations: alter-casting. Alter-casting is an obligation reminder carried out by referring to the other's status, such as "Motivated employees ought to work during their vacations as well." If one wants to accept the title of "motivated employee," he or she must also inherit the group obligations that come with it: "working during vacation."

In our paper, we start with the premise that certain covert or overt obligations are technostress creators. Technology can lead to overlapping obligations for employees. Whether they are individual or group obligations, we argue that these obligations can lead to technostress.

Ross (1970) argues that when we become aware of our unconscious habits that arise from covert obligations, we can choose to release the need to carry them. However, that is not always easy. The first step toward making covert obligations overt is identifying 
them. When they are discovered and articulated, they can leave the social arena (unarticulated norms that are inherited from our group membership status) and enter the group's political arena, where we can discuss, criticize, and make changes to our obligations.

This last argument drives our motivation for choosing obligation as an unlocking analytical device for technostress. We hypothesize that when employees become aware of their obligation-based habits, they can then either release the habits that lead to technostress (if they have control over them) or they can articulate them. By doing so, employees move these obligations from the realm of unconscious habits, as Ross (1970) calls them, to the political arena of the group, where they can be discussed and changed.

\section{Methodology}

We conducted interpretative research [19], with a hermeneutical approach to the analysis. We looked into the dialectic between the understanding of the text as a whole and the interpretation of its parts [19], as we describe below.

Our data consists of 10 semi-structured interviews [20] in two Danish organizations - each interview lasting between 30 and 60 minutes. Our informants are both managers (top-managers and middle-managers), and employees without leadership responsibilities. The questions that these informants had in common were related to whether they have heard about technostress prior to the interview, and what are their experiences in relation to technostress.

We used the technostress-creating dimensions presented in Table 1 to identify the type of technostress the interviewees described. Loyal to the hermeneutical approach, we entered the analysis with technostress-creating conditions and obligation categories in mind to see how these conditions and obligations were interwoven in the interviewees' accounts.

To afford a certain level of analysis, we focused on the concepts of individual obligations, group obligations, and obligation-based habits. We were also sensitive to our interviewees' evoked emotions, which can also indicate obligations.

We conducted our analysis based on verbatim transcriptions of the interviews by interpreting what the interviewees themselves described as technostress (e.g., evoking negative emotions or explicitly naming what they find stressful about technology). In that sense, we claim that we conducted content analysis (e.g., evoked emotions) [21].
We coded our interview material in several rounds. We first engaged in a preliminary reading of the interview material. Both authors checked and compared their understanding of how to code the different technostress incidents, hence engaging in coding with a priori goals [22].

We then engaged in the first round of coding by using the qualitative analysis software Atlas.ti. We coded the technostress incidents based on the parameters defined in Table 1, hence applying a structural coding strategy [22]. Whenever we found clear indications of technostress, we coded the incident accordingly. We considered the interviewees' use of the word stress and their evocations of feelings such as annoyance, frustration, or anger. For instance, the quote, "During your daily work, you need to relate to a lot of input [...], and that is definitely a stress factor" (Top manager, Company 2) was coded as "Techno-overload."

Next, we looked at the 116 resulting quotations in which interviewees suggested technostress and evaluated each one in relation to obligation. Scholars researching obligations often refer to it by using the verb ought to. Similarly, we looked for verbs that indicated the interviewees felt they owed something to themselves, each other, or the organization.

After the first round of coding, we conducted a second round using pattern coding. We looked at the obligations under each of the technostress-creating conditions and developed significant themes from the obligations we found [22] (e.g., "Relating to constant input"). These themes are reflected in Table 3.

From the quote above, we teased out the obligation "I ought to relate to a lot of input during my daily work" to highlight the relationship between technostress-creating conditions (techno-overload) and the obligation to relate to a lot of input during daily work. The resulting obligations are presented in Table 3 , "Technostress and obligations."

\section{Analysis}

In the following, we present an overview of the obligations and obligation categories we identified during our analysis (see Table 3.). We explain each of the obligation categories presented in the table, together with a representative quote. It is also noteworthy that the technostress-creating conditions based on Tarafdar et al. (2011) are overlapping. In our paper, we do not attempt a definitive distinction neither between technostress-creating conditions, nor between the obligation sub-categories we find as a result of our analysis. 
Further in the analysis, we observe individual and group obligations and obligation-based habits.

\subsection{Techno-overload}

Techno-overload is the most discussed technostress-creating condition among the interviewees. We categorize the obligations found under techno-overload under three themes: "Relating to constant input," "Keeping an overview," and "Managing ICT-related distractions."

Table 3. Technostress and Obligations
4.1.1. Relating to constant input. A common individual obligation theme among our interviewees is having to relate to constant input both during and outside working hours. Employees experience that it is their individual obligation to follow up with the constant stream of information they receive from different ICTs (e.g., email, chat, intranet, instant messaging on their company phone), and to prioritize the information and tasks received. Some employees report obligation-based habits, such as checking their emails off-work multiple times during the weekday,

\begin{tabular}{|c|c|c|}
\hline & $\begin{array}{l}\text { Obligation } \\
\text { category }\end{array}$ & Obligations \\
\hline \multirow[t]{3}{*}{$\begin{array}{l}\text { Techno- } \\
\text { overload }\end{array}$} & $\begin{array}{l}\text { Relating to } \\
\text { constant input }\end{array}$ & $\begin{array}{l}\text { I ought to relate to the input coming via ICTs } \\
\text { I ought to follow up with the input I receive via ICTs } \\
\text { I ought to be able to prioritize the input I receive via ICTs } \\
\text { I ought to remember the actions I need to take from the input I receive via ICTs } \\
\text { I ought to have control over the input I receive via ICTs }\end{array}$ \\
\hline & $\begin{array}{l}\text { Keeping an } \\
\text { overview }\end{array}$ & $\begin{array}{l}\text { I ought to organize the information I receive via ICTs } \\
\text { I ought to keep an eye on my inbox (ICTs) during vacation } \\
\text { I ought to always have an overview of my inbox (ICTs) } \\
\text { I ought to know which information to address, or is addressed to me (from ICTs) }\end{array}$ \\
\hline & $\begin{array}{l}\text { Managing } \\
\text { ICT } \\
\text { distractions }\end{array}$ & $\begin{array}{l}\text { We ought to be more conscious of ICT distractions } \\
\text { We ought to have discipline to avoid ICT stress } \\
\text { Others ought to contact me again via ICTs if their request is important enough }\end{array}$ \\
\hline \multirow[t]{2}{*}{$\begin{array}{l}\text { Techno- } \\
\text { invasion }\end{array}$} & $\begin{array}{l}\text { Constantly } \\
\text { connecting }\end{array}$ & $\begin{array}{l}\text { I ought to lose my work-home boundary to show that I love my work } \\
\text { I feel I ought to check my work phone throughout the whole day } \\
\text { I ought to be fine with checking emails (ICTs) on the weekend }\end{array}$ \\
\hline & $\begin{array}{l}\text { Reducing } \\
\text { stress }\end{array}$ & $\begin{array}{l}\text { I ought to check my work emails (ICTs) every day during vacation, due to a new } \\
\text { activity at work that requires attention to what is going on } \\
\text { I ought to check my emails (ICTs) in the morning to see what came through the } \\
\text { night so I can have a more relaxed attitude coming into the office } \\
\text { I ought to be prepared when going to work, therefore I check ICTs on my phone } \\
\text { when I come home, before and after dinner, and before I go to work } \\
\text { I ought to check ICTs while at home to reduce overall stress for the team }\end{array}$ \\
\hline \multirow[t]{2}{*}{$\begin{array}{l}\text { Techno- } \\
\text { complexity }\end{array}$} & $\begin{array}{l}\text { Monitoring } \\
\text { ICTs }\end{array}$ & $\begin{array}{l}\text { I ought to keep pace with the input received via ICTs } \\
\text { I ought to monitor all the different ICTs } \\
\text { I ought to figure out how to best use new ICTs } \\
\text { It should not be mandatory to have a common communication strategy for the } \\
\text { different ICTs } \\
\text { Others ought to like the ICTs we use in the department } \\
\text { We ought to have the option to use the ICTs we like }\end{array}$ \\
\hline & $\begin{array}{l}\text { Administering } \\
\text { ICTs }\end{array}$ & $\begin{array}{l}\text { The average employee ought to relate to } 20 \text { IT systems, each with its own } \\
\text { upgrades, notifications, and passwords } \\
\text { Others ought to be able to reach me if it's urgent; thus, it is difficult to switch off } \\
\text { ICT notifications completely } \\
\text { I ought to remember to deactivate and disable ICT notifications to avoid being } \\
\text { interrupted }\end{array}$ \\
\hline $\begin{array}{l}\text { Techno- } \\
\text { uncertainty }\end{array}$ & $\begin{array}{l}\text { Constantly } \\
\text { learning }\end{array}$ & $\begin{array}{l}\text { I ought to be able to motivate people to learn new technology/ICTs } \\
\text { I ought to make my employees realize they really need to change and be able to } \\
\text { learn new technology/ICTs throughout their entire career experience } \\
\text { We all ought to change in order to adapt to new technology/ICTs } \\
\text { We ought to continuously develop our technological/ICT skills }\end{array}$ \\
\hline
\end{tabular}


weekends, or vacations, in order to assess relevance to them. Some engage in the act of remembering what they are supposed to answer to or take action on upon returning to the office. Furthermore, they devise various strategies to remember, including setting reminders on their calendar (obligation-based habits).

"During your daily work, you need to relate to a lot of input [...], and that is definitely a stress factorboth keeping pace with it, but also follow up" (Top manager, Company 2).

The top manager describes in a generalized way how "you" need to relate to much input (individual obligation) coming from the different ICTs used at Company 2 . He sees that as "definitely a stress factor," as he indicates feeling obligated to "both [keep] pace with it," and also "follow up."

4.1.2. Keeping an overview. Employees feel it is their individual obligation to keep an overview by keeping an eye on their inbox during off-work times, by knowing which information is directed to them and which information is not, and by organizing the information received via ICTs (obligation-based habit).

"When I have a very full Outlook email inbox, that can actually stress me until I have identified which emails I should address and not" (Employee 4, Company 1).

Employee 4 from Company 1 reports that what stresses her is having a full inbox and not knowing which emails are addressed to her, and "which emails I should address and not." This indicates her individual obligation to have an overview of which emails are addressed to her.

\subsubsection{Managing ICT-related distractions.} Employees report feeling obligated to be more conscious and disciplined about how they spend their time, given the level of distractions in their environment. We find that one way for employees to manage distractions is by ignoring them and expecting their colleagues to reach out to them multiple times if a request is urgent enough (group obligation), thereby contributing to an increase in the number of distractions.

"We really have to be much more conscious about spending your time right, because the level of distraction is pretty high, right. [...] So, I think it requires quite a bit of discipline to not go into distraction mode and to avoid stress related to that" (Top manager, Company 1).

The top manager from Company 1 reports having to "be much more conscious about spending your time right." She reports that it takes "quite a bit of discipline" to "avoid stress" due to ICT-related distractions, indicating an individual obligation to be disciplined and avoid technostress.

\subsection{Techno-invasion}

Employees describe techno-invasion as either being constantly connected and available for work, or as a strategy to reduce stress by being prepared when coming to work.

4.2.1. Constantly connecting. A common theme for all employees is continuously connecting to work and feeling pressured to lose their work-home boundaries in order to show that they care about their work. Most employees report working during evenings, weekends, and vacations. The top manager and the middle manager from Company 2 justified their constant connectivity by stating that they want to signal their availability (individual obligation), hence reinforcing a group obligation of availability outside working hours.

"Coming home, check my phone. Before dinner I check my phone, after dinner, in the morning before I go to work, I would always check my phone as well. [...] It is nice because then I'm prepared" (Employee 3, Company 1).

Employee 3 reports checking her company phone several times throughout a regular weekday: "coming home," "before dinner," "after dinner," and "in the morning."

Additionally, several employees report comments made by their spouses or children related to their use of mobile devices to work from home. These comments signal a tension between their work and family obligations.

4.2.2. Reducing stress. Being perpetually connected sometimes comes with a reward: that of reducing stress, as we see in the example below.

"If there's something that I know that I might have to deal with, I'll deal with it, because then that reduces stress overall for the team. I also have a tendency to, before I even leave home in the morning, check what's coming through the night, um, but, but it allows a more relaxed attitude coming into the office." (Employee 1, Company 1).

Employee 1 from Company 1 reports that checking her phone at home and engaging in work tasks will reduce "stress overall for the team," suggesting her individual obligation to reduce stress for the group. Further, in order to have "a more relaxed attitude coming into the office," she feels the need to check the emails received during the night, suggesting that she feels obligated to have a relaxed attitude at work. This 
individual obligation contributes to group obligations of having a relaxed attitude at work.

\subsection{Techno-complexity}

Employees discuss techno-complexity either from the perspective of the many ICTs they need to monitor or from the perspective of managing distractions and notifications.

4.3.1. Monitoring ICTs. A predominant group obligation theme is monitoring the different ICTs employees need to perform their work tasks. Employees report feeling obligated to keep pace with all the ICTs, monitoring them, and figuring out how to best use them. Surprisingly, our data indicates a predicament: although having many communication channels without clear norms around them causes technostress, employees indicate that it should not be mandatory to adhere to a strict communication strategy.

"We have a lot of new channels now, new applications that we are learning [...] I think I have felt that I was getting stressed because of this, because of having too many things coming from different places and try to figure out how to use them best" (Employee 1, Company 1).

Employee 1 from Company 1 reports that there are "a lot of new channels" at the company she works for. Moreover, she reports "getting stressed" as she feels it is her personal obligation to "figure out how to use them [new applications] best."

4.3.2. Administering ICTs. Multiple ICTs come with multiple notifications, upgrades, and passwords. The Top manager from Company 1 points out that an average employee at the company has to relate to around 20 IT systems and each system comes with its upgrades, notifications, and passwords. Employees report that it is their individual obligation to know how to deal with these.

"Another thing you have to administer is, like, that the notifications and how they disturb you. [...] But, you know, on the other hand you have to, um, like, people should be able to reach you if they need you urgently $[\ldots]$ notifications are-they are useful but they can also distract you and distress you" (Employee 1, Company 1).

On the one hand, Employee 1 from Company 1 suggests feeling obligated to oversee the notifications and "how they disturb you." On the other hand, she also suggests feeling obligated to be available for her colleagues, who "should be able to reach you if they need you urgently." Her answer indicates a tension between her individual obligations to perform concentrated (undisturbed) work and the individual obligation to be reachable.

\subsection{Techno-uncertainty}

4.4.1. Constantly learning. Constant learning is an aspect explicitly discussed by the two top managers, but only implicitly addressed by other employees (e.g., see quote under the chapter "Administering notifications"). Employees report a group obligation to change, grow, learn, and continuously develop skills and capabilities. Learning is presented as a condition for survival as an employee in the company due to the constant introduction of new technologies.

"The parameter that could induce some stress also is if you're facing new technology. I have a few employees that say, 'I would not like to learn anything more,' for instance. And that is super, super hard to move those people" (Top manager, Company 2).

The top manager from Company 2 acknowledges the introduction of "new technology" as a stress factor for a "few employees," together with his individual obligation, as a top manager, to "move those people."

\subsection{Techno-insecurity}

The employees we interviewed neither discussed nor mentioned feeling that the introduction of ICTs threatened their jobs.

\section{Discussion}

In our study, we set out to answer the research question, "What can the sociological analytical concept of obligation reveal about ICT-related technostress in organizations?" The analysis chapter reveals some of the individual and group obligations that our knowledge workers consciously or unconsciously experience, as well as some of their obligation-based habits.

Our main finding is that certain obligations are technostress creators. We find that individual obligations are not only inherited from group obligations, but also contribute to the creation and enforcement of group obligations. Carrying out group and individual obligations leads to the creation of obligation-based habits. Our study is the only one, to our knowledge, that explores how individual obligations shape employees' habits (obligation-based habits) and lead to the creation of group obligations, and the only qualitative study on technostress within IS research. 


\subsection{Technostress-creating conditions and obligations}

We start our analysis with the technostresscreating conditions described by Tarafdar et al. (2011), with a focus on identifying obligations (group, individual, or habits). However, we add depth to the conditions proposed by Tarafdar et al. (2011) by showing how many different subcategories and obligations can be listed under each technostresscreating condition, thus adding more nuance to each of these conditions.

For example, Tarafdar et al. (2011) point out that the techno-overload dimension refers, among others, to employees feeling forced by ICTs to work much faster or to have a higher workload. We add to this previous knowledge by showing how, for the knowledge worker, techno-overload means engaging in additional work related to constant input: scanning, organizing, prioritizing, following up, and remembering. Additionally, we find that these obligation-based habits are rooted in an individual obligation of having an overview and having control over one's inbox. Missing the overview and control can lead to stress and anxiety, as our respondents inform us.

Another example is techno-complexity. Here we find that, in addition to the argument by Tarafdar et al. (2011) that employees feel pressured to learn and understand how to use new ICTs, ICTs are particularly stressful for the employees we interviewed due to the unspoken norms and tension between overlapping individual obligations. In particular, employees report feeling insecure and frustrated about lack of knowledge related to which channels to use for which type of communication; the overlap between ICTs used similarly; the lack of a common and mandatory communication strategy; notifications set on default to disturb; and ICTs used for both casual and urgent communication. ICTs used for both casual and urgent communication create a tension between the individual obligations of being available and conducting focused work, which cannot be carried out simultaneously.

\subsection{How obligations are shaped}

As Bergson (1977) points out, in order to carry out our individual obligations, we create habits. At the same time, Bergson (1977) and Rose (1970) highlight group-level obligations as easily transferred to the individual who belongs to a particular group; otherwise, the individual would have difficulty belonging.
Taking "constantly connecting" as an obligation subcategory found during our analysis, we find that leaders feel an individual obligation to be reachable by their employees, and therefore they signal their offwork availability. This leads to a normalization of availability outside working hours, thus enforcing a group obligation for employees as well.

However, the obligation-based habits of constantly connecting create a strain on family life. Multiple employees reveal that their spouses or children comment on our respondents' use of ICTs when at home, which is also in line with findings by Tams et al. (2020) and Barley et al. (2011).

At the same time, some admit to feeling curious or committed, or calling their inbox their "beloved," suggesting that for some, it is their individual obligation to be committed to their job that drives their obligation-based habits of constantly connecting. Regardless of the reason, these individual obligationbased habits contribute to group obligations of availability and lead to obligation-based habits of constantly connecting.

\subsection{Strategies for avoiding technostress}

It is not new that employees are receiving input constantly. We find that employees receive input and scan for what is important to them, as Mazmanian et al. (2013) and Barley et al. (2011) have found; however, our data also shows that employees engage in remembering tasks they need to take action on. A novel finding in technostress research is that employees build habits of adding reminders in their calendars for the tasks they cannot take action on in the present. This indicates that the individual obligations of relating to constant input and keeping an overview also lead to additional habits that occupy their time.

Another important finding is that employees report feeling obligated to be disciplined and more conscious about how to spend their time, and feel it is their personal obligation to avoid (techno)stress. It becomes evident that besides information overload, interruptions, and multitasking, which previous research on technostress points out [6], employees engage in additional obligation-based habits to remember, prioritize, keeping an overview, being disciplined, and trying to avoid (techno)stress. Thus, employees see technostress as their individual responsibility rather than a shared responsibility or an organizational one.

On the other hand, employees construct obligationbased habits [18] to check their ICTs in the morning or evening, on weekends, or during vacations. They engage in these habits due to their individual 
obligations to have a relaxed attitude and feel prepared when coming to work, to avoid feeling overwhelmed at work, or to avoid being a burden for other team members. These individual obligations indicate that employees feel it is their responsibility to manage their technostress.

\subsection{Practical implications}

To handle technostress in the workplace, organizations need to accept responsibility for both discussing and handling the obligations that lead to technostress. This requires, first, openness about these issues, which can be difficult as these matters may be surrounded by shame and guilt. Having a forum to discuss felt obligation and (techno)stress can make a difference.

A specific issue that needs to be handled is technostress as an organizational responsibility requiring organizational solutions. A starting point could be taking the obligations found in this study, summarized in Table 3, and exploring via a qualitative survey to what extent employees relate to these obligations. For example, if organizations find that "I ought to relate to the input coming via ICTs" (Table 3) is a common individual obligation, this could be renegotiated. A way to negotiate this obligation could be to agree upon which ICTs to prioritize (e.g., email), to agree that other ICTs are to be down-prioritized, and to agree that individuals are not expected to relate to the input coming via the down-prioritized ICTs.

Organizations have to remember that the consequences of not handling technostress are grave for both the individual (e.g., health problems, addiction, fatigue, exhaustion, negative affectivity) and the organization (e.g., reduced commitment from individuals, reduced capacity for creativity and innovation, job dissatisfaction, negative attitudes towards technology in general) $[2-6,8,16]$. Tackling technostress from a sociological perspective rather than a technological or an individual perspective can empower organizations.

\section{Conclusion}

With our study, we answer the research question "What can the sociological analytical concept of obligation reveal about ICT-related technostress in organizations?" by showing how certain obligations are technostress creators. We find that beyond the material properties of the ICTs [5,6], and beyond norms surrounding the usage of ICTs that lead to technostress $[9,13]$, individual and group obligations and obligation-based habits also contribute to technostress.

Our main contributions are theoretical and methodological. Theoretically, we contribute to IS research on technostress by employing the sociological lens of obligation [11], a theory that is novel to IS. Methodologically, we contribute to IS research on technostress by investigating technostress from a qualitative perspective, which is a new way of looking at it.

An important discovery is a tension that we find in overlapping individual obligations, for example, feeling obligated to be available, but also to conduct focused work, obligations that cannot be carried out simultaneously.

Furthermore, we note that employees feel it is their individual obligation to avoid technostress, and they devise strategies to cope with technostress-creating conditions. Their efforts add to their technostress and reinforce group obligations that can lead to technostress for the collective.

We contribute to practice by revealing employees' felt obligations that contribute to ICT-related technostress. Organizations can move these articulated obligation-habits that lead to technostress from the realm of unconscious habits, as Ross (1970) calls them, to the political arena of the group where they can be discussed and altered. That is, by discussing obligations explicitly, organizations can use obligations to alleviate technostress for employees. For example, organizations could discuss options for splitting the day into time slots when employees can engage in focused work and time slots allocated for information exchange.

\section{Limitations}

In this chapter, we present some of our paper's limitations. First, we acknowledge that we are working with limited data and therefore cannot make claims related to the universality of the obligations we have found. For example, this study was conducted in Denmark. The results of a similar study might differ in another cultural context. More specifically, technoinsecurity might be more prominent in a country with less job security than Denmark.

Our study is based only on interview data, which we also see as a limitation. Future studies might choose to add more data sources, such as survey data.

Another limitation is that employees and leaders might experience different types of individual obligation. For example, we find that leaders feel it is their individual obligation to motivate employees to adapt to new ICTs, which is not common in employees 
without managerial responsibilities. However, these differences are outside the scope of our study.

We also have to add two methodological limitations that are common to technostress research. One is related to whether we are dealing with episodic or chronic (techno)stress. Due to our approach's sociological nature, we cannot answer whether the technostress incidents are episodic or chronic. Another methodological limitation is that we cannot say whether the technostress reported by employees is positive or negative (or both).

\section{References}

[1] Weil M. M., L.D. Rosen, "Technostress: Coping with technology@work@ home@ play", Wiley, New York, 1997.

[2] S. Tams, M. Ahuja, J. Thatcher, V. Grover. "Worker stress in the age of mobile technology: The combined effects of perceived interruption overload and worker control", The Journal of Strategic Information Systems, 2020.

[3] M. Tarafdar, C. L. Cooper, J. Stich. "The technostress trifecta - techno eustress, techno distress and design: Theoretical directions and an agenda for research", Information Systems Journal, 2019, pp. 6-42.

[4] M. Tarafdar, C. Maier, S. Laumer, T. Weitzel, "Explaining the link between technostress and technology addiction for social networking sites: A study of distraction as a coping behavior", Information Systems Journal, 2020, pp .96-124.

[5] R. Ayyagari, V. Grover, R. Purvis, "Technostress: Technological Antecedents and Implications", MIS Quarterly, 2011,pp. 831.

[6] M. Tarafdar, Q. Tu, T.S. Ragu-Nathan, B.S. RaguNathan, "Crossing to the dark side: examining creators, outcomes, and inhibitors of technostress", Communication of the ACM, 2011, pp. 113.

[7] J. Wajcman, E. Rose," Constant Connectivity: Rethinking Interruptions at Work", Organization Studies, 2011, pp. 941-61.

[8] J.F. Stich, M. Tarafdar, P. Stacey, S.C. Cooper, "Appraisal of Email Use as A Source of Workplace Stress: A Person-Environment Fit Approach," Journal of the Association for Information Systems, 2019, pp. 132-60. [9] S.R. Barley, D.E. Meyerson, S. Grodal. "Email as a Source and Symbol of Stress," Organization Science, 2011, pp. 887-906.

[10] R. Riedl, H. Kindermann, A. Auinger, A. Javor, "Technostress from a Neurobiological Perspective: System Breakdown Increases the Stress Hormone Cortisol in Computer Users," Business and Information Systems Engineering, 2012, pp. 61-9.

[11] Clark C., "Emotions and Micropolitics in everyday life: some patterns and paradoxes of place.” In: T.D. Kemper, "Research Agendas in the Sociology of
Emotions", State University of New York Press, 1990. pp. 305-333.

[12] Ross R., "Obligation: a social theory," University of Michigan Press, 1970.

[13] M. Mazmanian, W. J. Orlikowski, J. Yates, "The Autonomy Paradox: The Implications of Mobile Email Devices for Knowledge Professionals", Organization Science, 2013, pp. 1337-1357.

[14] Selye H., "Stress in health and disease," Butterworths, 1976.

[15] Cooper C. L., Dewe P. J., O’Driscoll M., "Organizational Stress: A Review and Critique of Theory, Research, and Applications," SAGE Publications, 2001.

[16] S. Tams, K. Hill, A. Guinea, J. Thatcher, V. Grover V., "NeuroIS-Alternative or Complement to Existing Methods? Illustrating the Holistic Effects of Neuroscience and Self-Reported Data in the Context of Technostress", Journal of the Association for Information Systems, 2014, pp. $723-53$.

[17] S. Schellhammer, R. Haines, S. Klein, "Investigating Technostress in situ: Understanding the Day and the Life of a Knowledge Worker Using Heart Rate Variability", 46th Hawaii International Conference on System Sciences, Wailea, HI, USA, 2013, pp. 430-439.

[18] S. Krishnan, "Personality and espoused cultural differences in technostress creators", Computers in Human Behavior, 2017, pp. 154-67.

[19] Bergson H., "The two sources of morality and religion," University of Notre Dame Press, 1977.

[20] Alvesson M, Sköldberg K.," Reflexive methodology: New vistas for qualitative research", Sage Publishing, 2017.

[21] Bryman A, Bell E., "Business research methods", Oxford University Press, New York, NY, 2011.

[22] Wetherell M., "Affect and emotion: a new social science understanding", Sage Publishing, Los Angeles, London, 2012.

[23] Saldaña J., "The coding manual for qualitative researchers", Los Angeles, California, Sage, 2009. 